\title{
RULES TO LIVE BY, LAUDATO Sl', AND ALL OF US
}

\author{
JAMES A. F. STONER \\ Gabelli School of Business \\ Fordham University \\ New York, New York, U.S.A. \\ stoner@fordham.edu
}

In The Serengeti Rules: The quest to discover how life works and why it matters, Sean B. Carroll explores how pioneering researchers investigated questions such as "How does life work?" and "How does nature produce the right numbers of zebras and lions on the African savanna, or fish in the ocean?". And why the answers they found to questions such as these are important to us today as we grapple with some of our current problems-especially those of global unsustainability.

In the final chapter, titled "Afterward: Rules to Live By," Carroll writes: "I asserted at the outset of this book that our increasing mastery of biology was a major catalyst to the dramatic changes in the quantity and quality of human life over the past century." He then asks, "What role, then, will biology play in human affairs in the coming century?"1

After a brief summary comment on past contributions of biology to the well-being of our own and other species that he has explored throughout the book and noting some possible future contributions, he writes:

But as desirable as such advances may be, they are not the most pressing challenge for biologists and society. Rather, it is the declining health of our home and what that means for the ability of the Earth's ecosystems to support human life, let alone other creatures. We have created the extraordinary ecological situation where we are the top predator and the top consumer in all habitats. As Robert Paine warns, "Humans are certainly

'The passages from The Serengeti Rules are quoted with the permission of Sean B. Carroll and his publisher, Princeton University Press, for which we extend our thanks. 
the overdominant keystones and will be the ultimate losers if the rules are not understood and global ecosystems continue to deteriorate." Now the only species that can regulate us is us.

If the motto for the twentieth century was "Better Living through Medicine," the motto for the twenty-first must be "Better Living through Ecology." Fortunately, it is not just scientists who are deeply worried or who recognize the primacy of ecology. You may be surprised by who said the following (I certainly was):

Frequently, when certain species are exploited commercially, little attention is paid to studying their reproductive patterns in order to prevent their depletion and the subsequent imbalance of the ecosystem.... Caring for ecosystems requires far-sightedness.... Where certain species are destroyed or seriously harmed, the values involved are incalculable. We can be silent witnesses to terrible injustices if we think that we can obtain significant benefits by making the rest of humanity, present and future, pay the extremely high costs of environmental deterioration.

The author is Pope Francis, who issued an extraordinary Encyclical Letter on the environment in June 2015 titled "On care for our common home." Encyclicals are typically used to address the Catholic hierarchy on major issues of doctrine. In this exceptional instance, the pontiff expressed his wish "to address every person living on this planet" and "to enter into a dialogue with all people about our common home."

The 183-page document is equally remarkable for its ecological scope as for its candor. After systematically assessing the numerous types of degradation, including pollution and climate change, contamination of water, and the loss of biodiversity and species extinction, and their humanmade causes, Pope Francis states:

We need only take a frank look at the facts to see that our common home is falling into serious disrepair.... We can see signs that things are now reaching a breaking point, due to the rapid pace of change and degradation.

The pope certainly concurs that if we are going to make it into the next century with sufficient water, productive land and seas, and the food to support perhaps 10 billion people, as well as preserve the existence of our fellow creatures, the rules of ecology are going to have to become rules to live by. Indeed, he calls for a global "ecological conversion," using the latter term in both its spiritual and everyday connotations as a profound change of heart and mindset. (Carroll, 2016: 203-204)

Pope Francis's explicit calls for dialogue on the need for ecological conversion and his gently phrased calls for action to protect and nurture 
our common home have been echoed in many places, including in the pages of the Laudato si' themed issue (Vol. 5, No. 1) of this journal, guest-edited by Allen Tropea-Gray. Pope Francis's calls also contributed to the resolution passed on July 18, 2016, at the combined World Forum of the International Association of Jesuit Business Schools (IAJBS) and Annual Meeting of the Colleagues in Jesuit Business Education (CJBE) in Nairobi, Kenya:

The annual meeting of the IAJBS requests the IAJBS leadership, CJBE leadership, and the rest of the network of Jesuit business schools to work together to apply for the MacArthur Foundation 100 million dollar $100 \&$ Change competition with a project to transform Jesuit business education to be fully aligned with the wisdom in Laudato Si', with our universally-valid Jesuit educational tenets, and with the need for global sustainability, social justice, and poverty alleviation.

The articles in this issue of the Journal continue in this broad vein. The pieces by Kent Fairfield, Carl Obermiller \& Matt Isaac, and Maggie Eusebio bear quite directly on the concerns expressed by Pope Francis and on opportunities for constructive actions we can take in response to them; those by Michael Urick, Muyang Li, Selin Konur, \& Terrance Smith and Marinilka B. Kimbro, Ajay T. Abraham, C. Jay Lambe, \& Victoria Jones also provide guidance on how we can take the kinds of actions that will help us grapple with the problems we have created for ourselves and our children's' children.

Building our way of being in the world on a sustainability mindset is one step-perhaps the most important-for each of us. In "Educating for a Sustainability Mindset," Kent Fairfield builds on his teaching experiences in addressing the problem of helping students and others acquire the knowledge, perspectives, and commitments needed for the "ecological conversion" Pope Francis and many others have called for. He observes that well-equipped young professionals increasingly need to acquire exposure to and critical thinking about environmental, societal, political, and business issues, whether this be necessary simply as a context for work or for the centerpiece of their responsibilities.

Reflecting on his work in a business school, he notes that basic competence today requires knowledge of climate change, systems thinking, and humanitarian issues. Graduates must be acquainted with confounding business challenges as well as with what the most sustainable companies are doing now. Indeed, Fairfield argues that conveying cognitive learning is just a starting point for teachers while acquiring it is only a base for the further growth of students. The truly 
educated have gained in-depth experiential learning that informs a new worldview. He feels that the most profound goal for teachers to aspire to is to enable students to begin to acquire a new mindset or a new "way of being," embracing one's feelings, life purpose, and identity. His article suggests ways all of us can work toward that goal-in our classrooms and beyond.

The greater awareness women have for our precarious ecological situation and their greater commitment to the kind of dialogue called for by Francis have been obvious to many of us for several years. In "Are Green Men from Venus?," Carl Obermiller and Matt Isaac build on the consistent sustainability research finding that women are more ecofriendly than men, a gap usually ascribed to differences in socialization. The research they report explores a corollary process-the cognitive association of environmentalism with femininity and the consequent negative responses of men arising from their efforts to safeguard their masculine identity. In two studies, they replicate the recent finding (Brough, Wilkie, Ma, Isaac, \& Gal, 2016) of a mental association between environmentalism and femininity (for both men and women) and the consequent reduction in the effectiveness of conventional environmental appeals to men.

Beyond documenting downstream effects of the implicit greenfeminine association on explicit judgments and men's behavioral intentions, they also investigated two approaches for overcoming implicit associations. In their first study, they examined whether advertising skepticism and/or sustainability literacy might moderate the consequences of the green-feminine association. Their finding was that those participants who were high in advertising skepticism were less likely to exhibit the green-feminine association in their explicit judgments. Neither study, however, found evidence that higher sustainability literacy eliminates or attenuates downstream consequences of the green-feminine association, even though the second study showed a general positive effect of sustainability literacy on responses to an environmental appeal.

Obermiller and Isaac also explored the possibility of offsetting the implicit green-feminine association by creating an environmental appeal with distinctly masculine brand positioning elements. Two versions of an environmental appeal were produced, one with masculine and the other with feminine brand elements. While men and women were equally responsive to the masculine brand positioning, the most positive responses to the feminine positioning were from women. 
The authors note that although higher sustainability literacy seems to result in more pro-environmental behavior in general, it does not appear to moderate downstream effects of the implicit green-feminine association. They are optimistic at the end of their work, however, that greater advertising skepticism may help reduce the impact of the green-feminine association, and that increasing sustainability literacy might reduce negative associations with environmentalism for men over the long-term.

It has been said in a non-trivial sense that "global unsustainability is a spiritual problem." In "Spirituality and Business Sustainability: A Case of Coffee Farms in Amadeo, Cavite," Maggie Eusebio emphasizes the close connection between spirituality and ecological conversion. Just as Pope Francis states in Laudato si', she notes that an internal spiritual conversion is required to bring about responsible behavior that would aid in healing our common home-a home that cries out because of the violence committed against it. She speaks of the farmland of Amadeo, Cavite as "our Sister, Mother Earth," urges that it is time to come to her aid, and that doing so can be accomplished through ecological and spiritual conversion.

To support her conviction that such a conversion will aid in the healing of our common home, Eusebio reports her research found that the sustainability of coffee farms in Amadeo is positively associated with the owners' intrinsic spirituality, that what she calls Godly stewardship of farmlands leads to more sustainable farms. She suggests that the results of her research can be extended to other types of businesses, implying that Godly stewardship of businesses would lead to more sustainable ones.

The purpose of the "Nairobi resolution" noted above is not to transform Jesuit business education for its own sake; rather, it is to use the reform of all of business education to transform the system of production, distribution, and consumption of those goods and services we need for our global community-to transform, in particular, how business organizations go about playing their role in society. Michael Urick, Muyang Li, Selin Konur, and Terrance Smith focus on the need to transform these global production practices. They build upon the parallels between what we have been learning for almost seven decades, in our attempts to bring into our organizations the quality revolution inspired by W. Edwards Deming, Joseph M. Juran, Kaoru Ishikawa, and many others, and the kind of much deeper transformation we will need going forward if we are to create a producing-distributing-consuming system consistent with a "flourishing" (Ehrenfeld, 2010) world. 
Urick et al. observe that cultures focused on operational excellence (OE), which allows for continuous improvement, waste reduction, and problem solving, can help organizations (and societies) achieve greater sustainability. Indeed, many researchers in past studies have focused on bringing the "tools" of OE into organizations and making them part of the organizations' cultures, but many organizations report challenges in moving toward this type of culture.

Urick and his colleagues argue strongly against too narrow a focus on purely technical challenges in bringing sustainability-consistent practices into organizations. They observe that research on cultural change suggests that social aspects in an organization seem to present a greater challenge than technical ones. Using a grounded theory approach to explore social aspects of OE cultures, they find that social aspects of work represent major barriers to implementing continuous improvement and operational excellence initiatives. We can assume by extension, then, that social aspects are very likely to offer similar, if not greater, barriers to transformation toward sustainable business practices.

The authors also report that social barriers to implementing OE can stem from interpersonal factors such as communication issues, an unwillingness of some colleagues to embrace change, and workplace relationships as well as from organizationally-based factors such as employee treatment (including level of accountability and empowerment), cultural values inherent in the organization, and formal organizational characteristics (including formal titles, commitment of leadership, size of group/groupthink, and education/training).

Urick et al. thus emphasize the importance of recognizing social barriers and finding social pathways to discover how to "climb Mount Sustainability," to use Ray Anderson's term for Interface's goal of becoming a company fully aligned with the need for a sustainable world (Ray Anderson Foundation, n.d.).

In "Corporate Social Responsibility: The Efficacy of Matched Alliances Between Not-for-Profits and Multinational Enterprises in Developed and Emerging Markets," Marinilka B. Kimbro, Ajay T. Abraham, C. Jay Lambe, and Victoria Jones focus on how multinational enterprises (MNEs) can increase the effectiveness of their global sustainability and corporate social responsibility (CSR) initiatives. Recognizing the importance of well-designed CSR endeavors and positive media coverage for achieving and maintaining effective CSR and sustainability programs, they investigate the market response to CSR initiatives when MNEs and notfor-profits (NFPs) form "matched" alliances. They discuss three such initiatives formed by MNEs and local NFPs with a good "match" of 
common objectives and complementary capabilities: Walmart's Katrina Assistance, Infosys's Campus Connect, and Unilever's Project Shakti.

Kimbro et al. measure the effectiveness of these CSR activities through a media-intensity time-series analysis. The results point to a strong increase in media coverage surrounding the CSR events of these three MNE/NFP matched alliances as well as to a stronger positive response when the MNE operates in a local rather than a foreign environment. This positive effect, moreover, is greater in emerging rather than developed markets.

Motivated by the desire to respond to the burgeoning literature that argues that consumers react to CSR initiatives with increasing skepticism, the authors posit two broad explanations to account for weak positive reactions to CSR activities: negative market-attribution, which tends to dominate the literature, and a less explored business process explanation. Negative market-attribution develops from the growing perception that CSR activities are "self-serving" and lack "legitimacy" given that firms can exploit and use CSR as a "green-washing" mechanism. Indeed, this view is shared by Pope Francis in Laudato si' (p. 40): "There are too many special interests, and economic interests easily end up trumping the common good and manipulating information so that their own plans will not be affected."

Weak positive responses to CSR and sustainability activities can also be attributed to ineffective operational processes. These weak responses can arise from misguided replications of market-based operational approaches for delivering CSR activities that ignore the fact that stakeholders in CSR contexts are very different from core-business customers. The same ineffective processes can also result from the lack of local, cultural, and situational understanding needed for effectively planning and executing CSR and sustainability initiatives.

Kimbro and her colleagues also discuss, develop, and test a framework with the potential to improve either CSR legitimacy or CSR operational processes-or both-which in turn could result in positive responses to CSR activities. The article thus contributes to the advance of global social responsibility in at least three ways. First, the model builds upon theories of CSR operational effectiveness and performance measurement. Second, the findings advance and expand three streams of research by integrating literature on alliances based on common objectives and complementary operational efficiencies, studies of CSR effectiveness and market response, and theories of public/private partnerships. Finally, this article provides a replicable template that MNEs and NFPs can use in working together to deliver CSR activities in both local and global 
environments as well as in developed and emerging markets, and to improve and enhance the effect of CSR actions that contribute to social justice, poverty alleviation, and a more sustainable world.

\section{Now what?}

The final question an MBA student directed to four guest speakers on energy issues and global sustainability a few years ago in class was direct and straightforward: "What is the greatest barrier to creating a sustainable world?" Each of the first three speakers quickly gave rich and sensible answers based on technical opportunities and problems they had discussed earlier in the session. The fourth speaker, who had clearly been listening attentively and appreciatively to the three answers and to the rationale on which they were based, paused before speaking, thought for a while more, and then said something along the lines of the following:

I believe the greatest barrier to creating a sustainable world is that we disempower ourselves. There are an almost infinite number of things we can do that will make a contribution, but-perhaps because there is no single, unique, silver bullet that will "solve the problem"-or perhaps because whatever we do will never be enough-or for some other reasons-we do nothing. But if each of us does something, we might inspire each other, and together we could change the world ... maybe.

Perhaps there is a kernel of truth in that statement. As Allen Tropea-Gray makes clear in the editorial of the Laudato si' themed issue of this journal (Tropea-Gray, 2017), there is an enormous assortment of things we can do individually and collectively to care for our common home. The challenge is not to find valuable, exciting, impactful, and personally rewarding things to do. The challenge is in being willing to settle for just one or just a few as we decide what to select and pursue ... and begin. As Chris Lowney says in his newest book (Lowney, 2018): "Our hurting world is plagued by challenges that can't be overcome unless we bring big heart and best selves to confront the world's ills. You didn't ask for that burden and opportunity, but you're here on the playing field at this moment in history.... The moment chooses you..." (pp. 81-82).

Maybe now is the time for each one of us to listen for the opportunity that calls to us most loudly and appealingly at this moment ... and to answer that call ... the call that may point to our "calling." 


\section{REFERENCES}

Brough, A., Wilkie, J., Ma, J., Isaac, M., \& Gal, D. 2016. Is eco-friendly unmanly? The green-feminine stereotype and its effect on sustainable consumption. Journal of Consumer Research, 43(4): 567-582.

Carroll, S. B. 2016. The Serengeti Rules: The quest to discover how life works and why it matters. Princeton: Princeton University Press.

Ehrenfeld, J. 2009. Sustainability by design: A subversive strategy for transforming our consumer culture. New Haven: Yale University Press.

Francis. 2015. Laudato si': On care for our common home. Vatican City: Libreria Editrice Vaticana.

Lowney, C. 2018. Make today matter: 10 habits for a better life (and world). Chicago: Loyola Press.

Ray Anderson Foundation. (n.d.). Climbing Mount Sustainability. Available at http://www.raycandersonfoundation.org/assets/pdfs/rayslife/ EssayClimbingMountSustanability.pdf (accessed May 24, 2018).

Tropea-Gray, A. P. 2017. Pope Francis, Laudato si', and integral ecology: Perspectives on a critical issue. Journal of Management for Global Sustainability, 5(1): 1-18. 